\title{
The Role of Curcumin on Apoptosis through The RASSF1 A and Bax Pathways in Breast Cancer
}

\author{
Nunung Ainur Rahmah ${ }^{1}$, Harliansyah ${ }^{1}$, Fransiscus D. Suyatna ${ }^{2}$, Mpu Kanoko ${ }^{2}$, Primariadewi \\ Rustamadji ${ }^{2}$, Joedo Prihartono ${ }^{2}$, Samuel Johny Haryono ${ }^{3}$, \\ Bethy Suryawati Hernowo ${ }^{4}$
}

\author{
${ }^{1}$ Faculty of Medicine, Universitas YARSI, Jakarta, Indonesia \\ ${ }^{2}$ Faculty of Medicine, Universitas Indonesia, Jakarta, Indonesia \\ ${ }^{3}$ National Cancer Center Dharmais Hospital, Jakarta, Indonesia \\ ${ }^{4}$ Faculty of Medicine, Universitas Padjajaran, Bandung, Indonesia
}

\begin{abstract}
Curcumin has been reported with an in vitro the cytotoxic effect on several human cancer cells. However, reports on the mode of action and detail mechanism of curcumin in breast cancer disease are limited. Hence, curcumin's effect on the human breast cancer cell line MCF-7 and MDA-MB-468 was investigated. The MCF-7 and MDA-MB-468 breast cancer cells line were given curcumin in several doses. The anti-proliferation activity of curcumin was determined using the MTS cell viability test and caspase- 3 activity was used to detect apoptosis using flowcytometry. The expression of Ras-association domain family 1 isoform A (RASSF1A) and Bax protein in cells was evaluated by ELISA analysis. Kruskal-Wallis followed by the Mann-Whitney test and the Spearman correlation tests were used to asses correlation among RASSF1A, Bax, and caspase-3. Cytotoxicity of curcumin on MCF-7 was lower than that of MDA-MB-468 $(75.73 \mu \mathrm{g} / \mathrm{mL}$ and $380.79 \mu \mathrm{g} / \mathrm{mL})$. The concentration of curcumin at $80 \mu \mathrm{g} / \mathrm{mL}$ induced apoptosis mainly through the intrinsic pathway by caspase- 3 activation. Curcumin also showed an anti-proliferative activity as shown by the increase of RASSF1A and Bax protein. Curcumin mediates anti-proliferative and apoptotic effect through the activation of RASSF1A and Bax. Our research data adds information about the role of curcumin in epigenetic events through RASSF1A protein.
\end{abstract}

Keywords: Bax, caspase-3, curcumin, MCF-7, MDA-MB-468, RASSF1A

\section{INTRODUCTION}

Breast cancer is the most common form of cancer present in women worldwide (Desantis, et al., 2014). Among all breast cancer types, triple-negative breast cancer (TNBC) is the most aggressive, difficult to treat and more likely to spread in diagnosed patients. Women with TNBC have poor prognosis with few treatment options, therefore, new therapeutic agents for this aggressive tumor are critically needed (Ismail-Khan \& Bui, 2010; Foulkes WD \& Smith IE, 2010).

Previous research found that flavonoids were capable to inhibit cancer cell proliferation and delay

Submitted: December 6, 2019

Revised: May 14, 2020

Accepted: May 16, 2020

*Corresponding author: nunung.ainur@yarsi.ac.id 
tumour progression via epigenetic modification and by regulating apoptosis related signaling pathways such as Ras association (RalGDS/AF-6) domain family member 1 isoform (RASSF1A) pathways (Cao, et al., 2018). Curcumin is one of the possible candidates as anti-breast cancer agents through epigenetic pathway (Teiten, et al., 2013). The mechanism of inhibition by curcumin on cancer cell growth has been studied on various cancer cells lines (Moghtaderi, et al., 2017; Tomeh, et al., 2019; Hasima \& Aggarwal, 2012; Zhou, et al., 2017) and thought that the mechanism is done through modulation of various biological activities including the activation epigenetic pathways (Koohpar, et al., 2015).

In most breast cancer cases, the expression level of estrogen receptor $\alpha(E R \alpha)$ is directly proportional to tumor growth. Therefore, the MCF7 cell model has been examined extensively to determine the mechanism of estrogen-stimulated growth in tumor (Holliday \& Speirs, 2011; Ford, et al., 2011; Subik, et al., 2010). On the other hand, MDA-MB-468 (estrogen-receptor negative) cells that are aggressive and invasive TNBC cells are known to be resistant to several anti-cancer agents (Ismail-Khan \& Bui, 2010; Holliday \& Speirs, 2011; Ford, et al., 2011; Subik, et al., 2010). Many work of literatures reported that curcumin can induce apoptosis in breast cancer cells that have ER-positive and triple-negative (Lv, et al., 2014; $\mathrm{Hu}$, et al., 2018; Huang, et al., 2017; Liu, et al., 2017).

The present study was aimed to investigate the cytotoxic effect and apoptosis induction of curcumin in MCF-7 and MDA-MB-468 cells line in vitro.

\section{MATERIALS AND METHODS}

\section{Materials}

MCF-7 and MDA-MB-468 breast cancer cell lines were purchased from ATCC (Manassas, VA, USA). Dubelco's minimum essential medium
(DMEM) (Gibco, New York, USA) supplemented with 10\% fetal bovine serum (Biowest, Riverside, USA), with $5 \%$ of the amphotericin, and $5 \%$ of the penicillin-streptomycin (Biosciences, San Jose, USA). Curcumin was purchased from Sigma Chemical Co. (St. Louis, MO, USA). The MTS kit was obtained from the Promega (Madison, USA). The RASSF1A kit was obtained from MyBiosource and Bax was obtained from Abcam. The caspase-3 activity was determined using PE-conjugated monoclonal active caspase-3 antibody apoptosis kit (BD Pharmingen, Heidelberg, Germany).

\section{Cell Culture}

MCF-7 and MDA-MB-468 cells were routinely cultured in tissue flask containing DMEM with $10 \%$ FBS, $5 \%$ penicillin/streptomycin, and 5\% amphotericin at $37^{\circ} \mathrm{C}$ in a humidified atmosphere with $5 \% \mathrm{CO}_{2}$. To determine the effects of curcumin on cell proliferation, cells from stock plates were suspended by treatment with $0.25 \%$ trypsin, buffered with $0.2 \%$ EDTA $(\mathrm{pH} 7.3)$ and counted using a hemocytometer. Cells were adjusted to a density of $1 \times 10^{6}$ cells/well to the required volume of plating medium supplemented with $10 \%$ PBS dan adds curcumin dissolved in DMSO (Klawitter, et al., 2012).

\section{Proliferation Study}

The breast cancer cells were seeded into 96-well plates at a density of 5,000 cells per well in triplicates and were treated with 1 , $50,100,150,200,250,300,350,400 \mu \mathrm{g} / \mathrm{mL}$ concentrations of curcumin for $48 \mathrm{~h}$ (according to the Promega datasheet). DMSO (0.1\%) was added to the control wells followed by incubation at $37^{\circ} \mathrm{C}$ for $2 \mathrm{~h}$ after addition of $20 \mathrm{mg} / \mathrm{mL} 3-(4,5$ dimethylthiazol-2-yl)-5(3-carboximetoniphenol)2-(4-sulphodenil)-2H-tetrazolium) (MTS) to each well. Absorbance was measured on optical density at $490 \mathrm{~nm}$. The $\mathrm{IC}_{50}$ was developed by an inhibition curve and recorded as the mean \pm standard deviation of three independent experiments. 


\section{Evaluation of RASSF1A and Bax}

The test kits were sandwich enzyme immunoassay. The optical density (OD) was determined using a microplate reader set at $450 \mathrm{~nm}$. The concentration of protein in the samples was determined by comparing the OD of the samples to the standard curve.

\section{Determination of Caspase-3 Activity}

The caspase- 3 activity was determined using flowcytometry according to the manufacturer's instructions. Cisplatin was used as the positive control and the untreated sample was used as the negative control. Fold-increase in caspase activity was determined by comparing the results of treated samples with the level of the untreated control. Statistical analysis. All statistical analyses were performed using the SPSS 20.0 statistical software for Windows. Statistical significance was determined using the Kruskal-Wallis test followed by the Mann-Whitney Posthoc for multiple comparisons. Statistical significance was set at $p<0.05$.

\section{RESULT}

\section{Curcumin Inhibited Proliferation on MCF-7 and MDA-MB-468 Cells}

The cell proliferation was inhibited by curcumin in a dose-dependent manner. The inhibitory concentration $50\left(\mathrm{IC}_{50}\right)$ values for the MCF-7 cells were detected at $75.73 \mu \mathrm{g} / \mathrm{mL}$ and the MDA-MB-468 cells were detected at 380.79 $\mu \mathrm{g} / \mathrm{mL}$. These results indicated that curcumin has potent anti-proliferative effect in breast cancer cells.

\section{Curcumin Induces Apoptosis on MCF-7 and MDA-MB-468 cells}

Our results showed that curcumin in a dosedependent manner induced apoptosis. As shown in Figure 1, the percentage of caspase-3 with a concentration of curcumin $70 \mu \mathrm{g} / \mathrm{mL}$ increased from $1.12 \%$ to $71.94 \%$, from $0.48 \%$ to $76.69 \%$ in MCF7 and MDA-MB-468 cells, respectively. Under the treatment with a concentration of curcumin $80 \mu \mathrm{g} /$ $\mathrm{mL}$, the caspase-3 increased to $94.75 \%$ and $93.55 \%$ in MCF-7 and MDA-MB-468 cells.

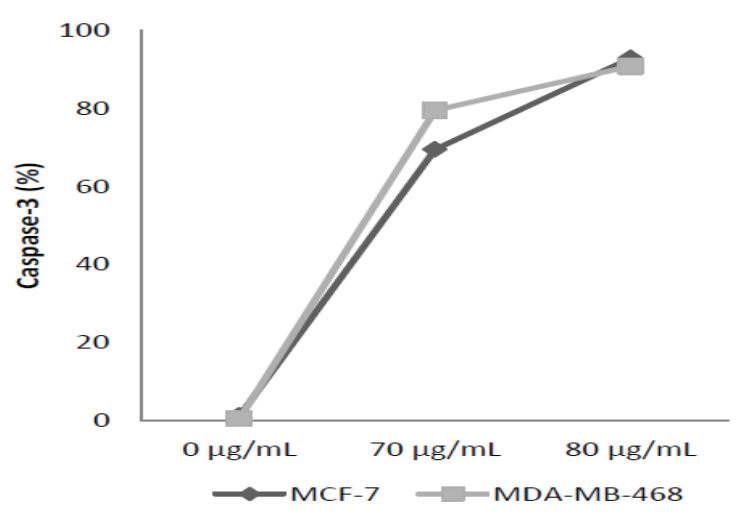

Figure 1. The regulatory effect of curcumin on apoptosis in (A) MCF-7 and (B) MDA-MB-468 cells. The cells were treated with a specific concentration of curcumin for $24 \mathrm{~h}$. Flowcytometry assay of curcumin-induced apoptosis cells for $24 \mathrm{~h}$ (in \%, Y axis); untreated, $70 \mu \mathrm{g} /$ $\mathrm{mL}$, and $80 \mu \mathrm{g} / \mathrm{mL}$ (dose, $X$ axis). Curcumin induced apoptosis cell on MCF-7 and MDA-MB-468 cells in a dose-dependent manner.

\section{Curcumin Up-regulated the Protein Expres- sion of RASSF1A on MCF-7 and MDA-MB-468 cells}

To investigate whether suppression of proliferation of breast cancer cells by curcumin is due to the downregulation of molecules involved in cell proliferation, we tested the protein levels of RASSF1A in cells. As shown in Figure 2 , at the previously demonstrated pharmacological effective (anti-proliferation and apoptosis) concentrations, curcumin could significantly increased the protein levels of RASSF1A on MCF7 and MDA-MB-468 cells. We found that curcumin treatment increases the protein expression of RASSF1A in a dose-dependent manner. Compared with MDA-MB-468 cells, the MCF-7 cells expressed an increased level of protein in RASSF1A. 

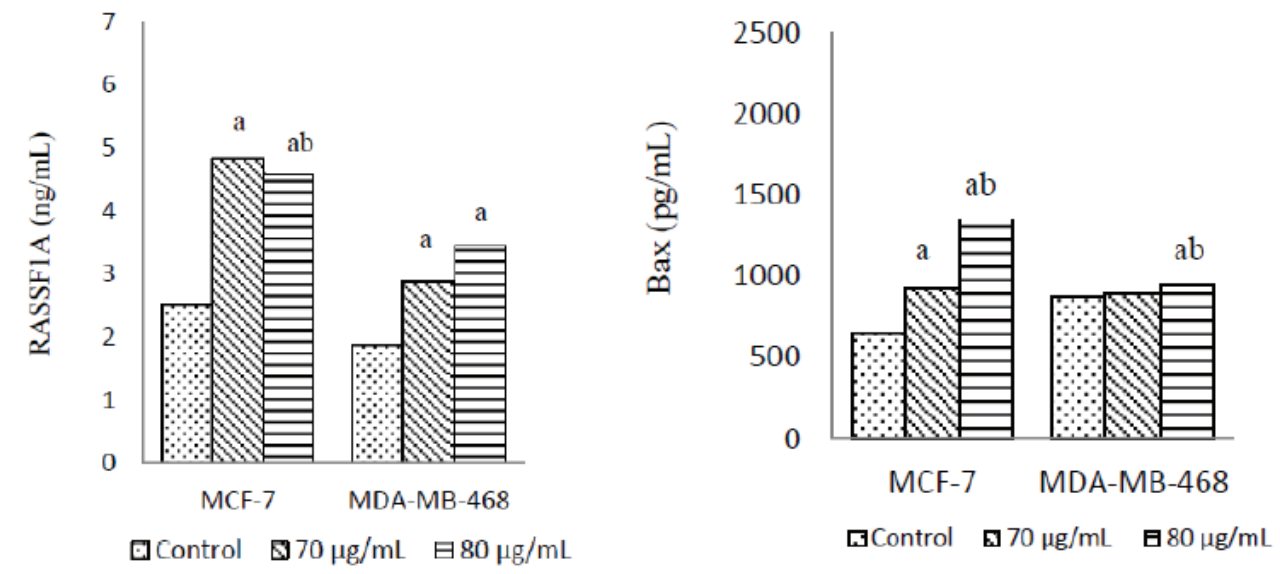

Figure 2. Curcumin up-regulated RASSF1A and Bax of protein on MCF-7 and MDA-MB-468 cells. (a. Statistical significance $(p<0.05)$ compared to the untreated for the respective time point, b. statistical significance $(p<0.05)$ compared to the treated group for $24 \mathrm{~h}$. (concentration, $Y$ axis; dose, $X$ axis)

\section{Curcumin Up-regulated the Protein of Bax on MCF-7 and MDA-MB-468}

We further investigated the mechanisms underlying curcumin-induced apoptosis in breast cancer cells. As shown in Figure 2, Bax levels were significantly up-regulated by curcumin in both cells in a dose-dependent manner.

\section{DISCUSSION}

Curcumin is a group of flavonoids that shows great potential as cancer chemopreventive agents in cell culture studies and it is known to have an anti-proliferation flavonoid. To be a potent anti-cancer in a biological system, a flavone should contain methoxy groups that metabolize faster to the conversion of flavonoid products (Sharma, et al., 2005). In the previous study of Pushpalatha, et al., $\mathrm{IC}_{50}$ curcumin was reported on MCF-7 cells using the $72 \mathrm{~h}$ incubation MTT method of 21.29 $\mu \mathrm{g} / \mathrm{mL}$. In the Koohpar, et al. study it was reported that $\mathrm{IC}_{50}$ curcumin on MCF-7 cells using the MTT method at $24 \mathrm{~h}$ incubation was $79.58 \mu \mathrm{g} / \mathrm{mL}$ and the results decreased after $48 \mathrm{~h}$ incubation (53.18 $\mu \mathrm{g} / \mathrm{mL})$ and $72 \mathrm{~h}(30.78) \mu \mathrm{g} / \mathrm{mL})$. In the study of $\mathrm{Hu}$, et al. It was reported $\mathrm{IC}_{50}$ curcumin on MCF-
7 cells using the $72 \mathrm{~h}$ MTT incubation method of $1.32 \mu \mathrm{M}$ (conversion of $0.49 \mu \mathrm{g} / \mathrm{mL}$ ) and on MDAMB-468 cells of $18.61 \mu \mathrm{M}$ (conversion of $6.85 \mu \mathrm{g}$ / $\mathrm{mL}$ ). It is difficult to obtain literature that states that research uses MTS. In this study, the $\mathrm{IC}_{50}$ of curcumin on MDA-MB-468 (triple-negative) cells was higher than that of MCF-7 cells $(75.73 \mu \mathrm{g} /$ $\mathrm{mL}$ and $380.79 \mu \mathrm{g} / \mathrm{mL}$ ), indicating that the MDAMB-468 cells were less sensitive than MCF-7 cells. The differences in the results of the average inhibition of curcumin lie on individual cell factors. Martin, et al. reported that gene modification or the microenvironment often resulted in changes in cell division (Martin, et al., 2009). The $\mathrm{IC}_{50}$ of curcumin on MDA-MB-468 results are consistent with the nature of triple-negative cancer cells that have an intermediate response to chemotherapy (Holliday and Speirs, 2011).

It is generally believed that the balance between proliferation and apoptosis influences the response of tumors to cytotoxic treatment. Apoptosis is considered as a significant form of cancer cell death after treatment with the cytotoxic drug and has been recognized as a standard strategy for the selection of anti-cancer drugs (Yew, et al., 2008). The caspase family of cysteine proteases plays a 
key role in apoptosis. Caspase- 3 is a key protease that is activated during the early stages of apoptosis and responsible for core apoptosis. Caspase-3 deficiency and down-regulation have been reported to be associated with breast carcinogenesis (McIlwain, et al., 2013; Ponder, et al., 2019; Larsen \& Sørensen, 2017). MCF-7, a breast cancer-derived cell line, is deficient of caspase- 3 and relatively insensitive to many chemotherapy. Reconstitution of caspase-3 sensitizes MCF-7 breast cancer cells to doxorubicin- and etoposide-induced apoptosis (Yang, et al., 2001; Wang, et al., 2016). The reports study have demonstrated the synergistic effects of paclitaxel in combination and alone with curcumin induced caspase-3 (Calaf, et al., 2018). In another research report that the administration of curcumin and neoadjuvant chemotherapy in patients with triple negative breast cancer increases caspase- 3 levels (Siregar, et al., 2017). This indicates that increased activity of caspase- 3 after treatment with curcumin may play an important role in cancer prevention and treatment.

Although the $\mathrm{IC}_{50}$ value of curcumin on MDA-MB-468 was higher than MCF-7, the administration of curcumin around MCF-7 of $\mathrm{IC}_{50}$ concentrations affected the increase in RASSF1A protein in MDA-MB-468, yet the effect was smaller than that of MCF-7. This result showed the potential anti-tumor effect of curcumin which was worthwhile to be investigated. A previous study reported that curcumin inhibits the activity of $\mathrm{M}$. SssI (bacterial DNA methyltransferase) which is a DNMT analog, through inhibition of catalytic thiolate C1226 DNA methyltransferase 1 (DNMT1) (Parashar, et al., 2012). The $\alpha$-carbon bis- $\alpha$, $\beta$-unsaturated ketone overlaps the C-6 atom of the cytosine ring in the catalytic space through the C-3 portion of keto curcumin. The covalent bond will inhibit DNMT1 activity without joining DNA (Liu, et al., 2009). Curcumin causes reactivation of RASSF1A expression in MCF-7 cells by inhibiting DNMT1 activity and in vivo reactivation of RASSF1A in MCF-7 cells implanted in mice
(Liu, et al., 2012). Curcumin also increases the RASSF1A protein by increasing mRNA in MCF7 and MDA-MB-468 (Du, et al., 2012). Increased RASSF1A protein levels in this study indicate that there is a possibility of epigenetic processes in the form of DNA methylation. Hypermethylation of RASSF1A causes suppression of RASSF1A gene function so that it will decrease RASSF1A protein. In contrast to genetic mutation, DNA methylation is susceptible to change and reversible (Goel \& Aggarwal, 2010; Basnet \& Skalko-Basnet, 2011). Hence, these results suggest that curcumin is an excellent agent that could be involved in DNA methylation changes and be useful for chemotherapy and chemoprevention. Reactivation of RASSF1A by curcumin will result in the restoration of their biological functions. Further research is needed to examine DNA methylation.

The other key cellular process that may be mediated by RASSF1A the regulation of apoptosis. The intrinsic pathway of apoptosis involves the activation of the proapoptotic members of the Bcl2 family using its function through mitochondria. Curcumin induces the release of cytochrome-c from mitochondria, causing activation of caspase 3 and the breakdown of Poly ADP ribose polymerase (PARP), which is a feature of caspase-dependent apoptosis (Wong, 2011). A previous study reported that RASSF1A can regulate Bax activity through direct binding to the apoptotic modulator (MOAP1), a protein that binds to Bax (Law, et al., 2015). Our results demonstrated that the curcumin increase Bax protein levels which resulted in increase caspase- 3 activity followed by apoptosis in MDA-MB-468 cells.

Our study showed that there was no correlation between RASSF1A protein levels and Bax protein levels in MCF-7 cells. Apoptosis can be induced by Mammalian sterile 20-like kinase-1 (MST1) without going through Bax. A previous study reported that ROS causes phosphorylation of MST1/2, causing thioredoxin to be released and binds to MST1 through the Salvador-RASSF1A- 
Indonesian Journal of Cancer Chemoprevention, June 2020 ISSN: 2088-0197

e-ISSN: $2355-8989$

Hippo (SARAH) domain. Furthermore, thioredoxin activates endogenous MST1/2 kinase, resulting in the division of MST1/2 fragments and binds to caspase-3 (Chae, et al., 2012). These results indicate that RASSF1A can increase apoptosis through the Bax and MST1 pathways in MCF-7 cells. We also find a correlation between RASSF1A protein levels and caspase-3 in MDA-MB-468 cells. Apoptosis in triple-negative breast cancer cells can occur through various pathways. $\mathrm{Hu}$, et al. (Hu, et al., 2018) reported that curcumin induces apoptosis in triple-negative breast cancer cells by inhibiting the activity of Akt/PKB (protein kinase B) and decreasing Bcl-2.

\section{CONCLUSION}

This study showed that the administration of curcumin treatment to MCF-7 and MDAMB-468 cells efficiently enhances the suppression of the growth of the breast cancer cells in vitro through reactivation of RASSF1A, upregulation of Bax and induction of apoptosis.

\section{ACKNOWLEDGMENT}

The author was grateful for the grant from the Technology and Higher Education, Republic of Indonesia (RISTEKDIKTI) and the YARSI University, Indonesia.

\section{REFERENCES}

Basnet, P. and Skalko-Basnet, N., 2011, Curcumin: An anti-inflammatory molecule from a curry spice on the path to cancer treatment, Molecules, 16(6), 4567-4598.

Calaf, G.M., Ponce-Cusi, R. and Carrión, F., 2018, Curcumin and paclitaxel induce cell death in breast cancer cell lines, Oncol. Rep., 40(4), 2381-2388.

Cao, X., Tang, Q., Holland-Letz, T., Gundert, M., Cuk, K., Schott, S., et al., 2018, Evaluation of promoter methylation of RASSF1A and ATM in peripheral blood of breast cancer patients and healthy control individuals, Int. J. Mol. Sci., 19(3), 900-912.

Chae, J.S., Hwang, S.G, Lim, D.S. and Choi, E.J., 2012, Thioredoxin-1 functions as a molecular switch regulating the oxidative stress-induced activation of MST1, Free. Rad. Biol.Med., 53(12), 2335-2343.

Desantis, C., Ma, J., Bryan, L. and Jemal, A., 2014, Breast Cancer Statistics, 2013, Cancer. J. Clin, 64(1), 52-62.

Du, L., Xie, Z., Wu, L.C., Chiu, M., Lin, J., Chan, K.K., et al., 2012, Reactivation of RASSF1A in breast cancer cells by curcumin, Nutr.Cancer., 64(8), 1228-1235.

Ford, C.H.J., Al-Bader, M., Bushra, Al-Ayadhi, B. and Francis. I., 2011, Reassessment of estrogen receptor expression in human breast cancer cell lines, Anticancer. Res., 31(2), 521-528.

Foulkes, W.D, and Smith IE, R.-F. J., 2010, TripleNegative Breast Cancer, New. Engl. J. Med., 363(20), 1938-1948.

Goel, A. and Aggarwal, B.B., 2010, Curcumin, the golden spice from Indian saffron, is a chemosensitizer and radiosensitizer for tumors and chemoprotector and radioprotector for normal organs, Nutr. Cancer, 62(7), 919-930.

Hasima, N. and Aggarwal, B.B., 2012, Cancer-linked targets modulated by curcumin, Int. J. Biochem. Mol. Biol., 3(4), 328-351.

Holliday, D.L. and Speirs, V., 2011, Choosing the right cell line for breast cancer research, Breast. Cancer. Res., 13, 215-222.

Hu, S., Xu, Y., Meng, L., Huang, L. and Sun, H., 2018, Curcumin inhibits proliferation and promotes apoptosis of breast cancer cells, Exp. Ther. Med., 16(2), 1266-1272.

Huang, L., Li, A., Liao, G., Yang, F., Yang, J., Chen, X., et al., 2017, Curcumol triggers apoptosis of p53 mutant triple-negative human breast cancer MDA-MB 231 cells via activation of p73 and PUMA, Oncol. Lett., 14(1), 1080-1088. 
Ismail-Khan, R. and Bui, M.M., 2010, A review of triple-negative breast cancer, Cancer. Control., 17(3), 173-176.

Klawitter, M., Quero, L., Klasen, J., Gloess, A.N., Klopprogge, B., Hausmann, O., et al., 2012, Curcuma DMSO extracts and curcumin exhibit an anti-inflammatory and anti-catabolic effect on human intervertebral disc cells, possibly by influencing TLR2 expression and JNK activity, J. Inflamm., 9(1), 29.

Koohpar, Z.K., Entezari, M., Movafagh, A. and Hashemi, M., 2015, Anticancer activity of curcumin on human breast adenocarcinoma: Role of Mcl-1 gene, Iran. J. Cancer. Prev., 8(3), e2331.

Larsen, B.D. and Sørensen, C.S., 2017, The caspaseactivated DNase: apoptosis and beyond, FEBS. J., 284(8), 1160-1170.

Law, J., Salla, M., Zare, A., Wong, Y., Luong, L., Volodko, N., et al. , 2015, Modulator of apoptosis 1 (MOAP-1) is a tumor suppressor protein linked to the RASSF1A protein, J. Biol. Chem., 290(40), 24100-24118.

Liu, J.L., Pan, Y. Y., Chen, O., Luan, Y., Xue, X., Zhao, J., et al., 2017, Curcumin inhibits MCF-7 cells by modulating the NF-KB signaling pathway, Oncol. Lett., 14(5), 5581-5584.

Liu, Z., Du, L., Liu, S., et al., 2012, Complementary reactivation of tumor suppressor genes in breast cancer cells by curcumin and curcumin O-glucuronide, Cancer. Res., 72, 581.

Liu, Z., Xie, Z., Jones, W., Pavlovicz, J.R.E., Liu, S., Yu, J., et al., 2009, Curcumin is a potent DNA hypomethylation agent, Bioorganic. Med. Chem. Lett., 19(3), 706-709.

Lv, Z.D., Liu, X.P., Zhao, W.J., Dong, Q., Li, F.N., Wang, H.B., et al., 2014, Curcumin induces apoptosis in breast cancer cells and inhibits tumor growth in vitro and in vivo, Int. J. Clin. Exp. Pathol., 7(6), 2818-2824.

Martin, D.N., Boersma, B.J., Yi, M., Reimers, M., Howe, T.M., Yfantis, H.G., et al., 2009, Differences in the tumor microenvironment between African-
American and European-American breast cancer patients, PLoS ONE, 4(2), e4531.

Mcllwain, D.R., Berger, T. and Mak, T.W., 2013, Caspase functions in cell death and disease, Cold. Spring. Harbor. Perspectives. Biol., 5(4), 1-28.

Moghtaderi, H., Sepehri, H. and Attari, F., 2017, Combination of arabinogalactan and curcumin induces apoptosis in breast cancer cells in vitro and inhibits tumor growth via overexpression of p53 level in vivo, Biomed. Pharmacother., 88, 582-594.

Parashar, G., Parashar, N.C. and Capalash, N., 2012, Curcumin causes promoter hypomethylation and increased expression of FANCF gene in $\mathrm{SiHa}$ cell line, Mol. Cel. Biochem., 365, 29-35.

Ponder, K.G., Lawrence, H. and Boise, L.H., 2019, The prodomain of caspase- 3 regulates its own removal and caspase activation, Cell. Death. Discover. , 5(1), 56-66.

Pushpalatha, R., Selvamuthukumar, S. and Kilimozhi, D., 2017, Comparative insilico docking analysis of curcumin and resveratrol on breast cancer proteins and their synergistic effect on MCF-7 cell line, J. Young. Pharm., 9(4), 480-485.

Siregar, K.M., Manuaba, T.W., Lubis, M.N.D. and Sembiring, R.J., 2017, Caspase 3 as prognostic marker for triple negative breast cancer chemotherapy, Asian. J. Pharmaceutical . Clin. Res., 10(11), 304-307.

Sharma, R.A., Gescher, A.J. and Steward, W.P., 2005, Curcumin: The story so far, Europ. J. Cancer., 41, 1955-1968.

Subik, K., Lee, J.F., Baxter, L., Strzepek, T., Costello, D., Crowley, P., et al., 2010, The expression patterns of ER, PR, HER2, CK5/6, EGFR, KI-67 and $A R$ by immunohistochemical analysis in breast cancer cell lines, Breast Cancer. Basic. Clin. Res, 4, 35-41.

Teiten, M.H., Dicato, M. and Diederich, M., 2013, Curcumin as a regulator of epigenetic events, Mol. Nutr. Food. Res., 57(9), 1619-1629.

Tomeh, M.A., Hadianamrei, R. and Zhao, X., 2019, 
A review of curcumin and its derivatives as anticancer agents, Int. J. Mol. Sci., 20, 10331059.

Wang, S., He, M., Li, L., Liang, Z., Zou, Z. and Tao, A., 2016, Cell-in-Cell Death Is Not Restricted by Caspase-3 Deficiency in MCF-7 Cells, J. Breast. Cancer., 19(3), 231-241.

Wong, R.S.Y., 2011, Apoptosis in cancer: From pathogenesis to treatment, J. Exp. Clin. Cancer. Res, 30, 87.

Yang, X.H., Sladek, T.L. and Liu. X., 2001, Reconstitution of caspase 3 sensitizes MCF7 breast cancer cells to doxorubicin- and etoposide-induced apoptosis, Cancer. Res., 16(1), 348-354.

Yew, H.C., Nordin, F.J., Thiam, T.T., Azimahtol, H.L.P., Abdullah, N.R. and Ismail, Z., 2008, Antiproliferative property and apoptotic effect of xanthorrhizol on MDA-MB-231 breast cancer cells, Anticancer. Res., 28(6 A), 3677-3689.

Zhou, Q.M., Sun, Y., Lu, Y.Y., Zhang, H., Chen, Q.L. and Su, S.B., 2017, Curcumin reduces mitomycin $C$ resistance in breast cancer stem cells by regulating $\mathrm{Bcl}-2$ family-mediated apoptosis, Cancer. Cell. Int., 17, 84-97. 